\title{
El caseinato de sodio y la caseína $\alpha$ inhiben la proliferación de la línea celular mieloide de ratón 32D clone 3 (32Dcl3) mediante el TNF- $\alpha$.
}

Benny Weiss-Steider ${ }^{1}$, Yolanda Córdova ${ }^{1}$, Itzen Aguiñiga-Sánchez ${ }^{1}$, Edgar LedesmaMartínez ${ }^{1}$, Vanihamin Domínguez-Melendez², Edelmiro Santiago-Osorio

${ }^{1}$ Laboratorio de Hematopoyesis y Leucemia, Facultad de Estudios Superiores Zaragoza, Universidad Nacional Autónoma de México, Ciudad de México, México

${ }^{2}$ Laboratorio de Biología Celular y Molecular, Centro de Estudios y Servicios en Salud, Universidad Veracruzana, Veracruz, México

Introducción. Se ha demostrado que el caseinato de sodio y sus componentes (caseínas $\alpha, \beta$ у к) inhiben la proliferación de la línea celular hematopoyética de ratón 32D clone 3 (32Dcl3) e inducen su diferenciación hacia macrófagos. Se sabe que la caseína a induce la producción de IL-1 $\beta$ y que esta última citocina inhibe la proliferación celular mediante la producción del factor de necrosis tumoral alfa (TNF- $\alpha$ ), pero se desconoce si el caseinato de sodio y las caseínas inducen la producción de TNF y si este es el responsable de la inhibición de la proliferación.

Objetivo. Evaluar si el caseinato de sodio y las caseínas $\alpha, \beta$ у к inhiben la proliferación de la línea celular 32Dcl3 mediante la producción de TNF-a.

Materiales y métodos. Se usaron diferentes concentraciones de caseinato de sodio y de las caseínas $\alpha, \beta$ y $\mathrm{k}$ en las células 32Dcl3. Posteriormente, se evaluaron la viabilidad celular mediante una prueba con el MTT [3-(4,5-dimetiltiazol-2-ilo)-2,5-difeniltetrazol], la inducción de apoptosis con la citometría de flujo y la síntesis del TNF- $\alpha$ con el ELISA. Además, se hicieron pruebas de neutralización con anti-TNF- $\alpha$ en células 32Dcl3 tratadas con caseinato de sodio y caseína a, y se evaluó la proliferación celular.

Resultados. Se encontró que el caseinato de sodio y las caseínas $\alpha, \beta$ y $\mathrm{k}$ reducían la proliferación de la línea celular 32Dcl3 sin afectar la viabilidad, y que solo el caseinato y la caseína a inducían la apoptosis y la liberación al medio de TNF-a. La proliferación de células $32 \mathrm{Dcl} 3$ tratadas con caseinato y caseína $\alpha$ se restableció al usar anticuerpos anti-TNF- $\alpha$.

Conclusión. El TNF-a fue el principal responsable de la inhibición de la proliferación en las células 32Dcl3 tratadas con caseinato de sodio o caseína $\alpha$.

Palabras clave: caseínas; hematopoyesis; proliferación celular; apoptosis; factor de necrosis tumoral alfa.

Sodium caseinate and alfa-casein inhibit proliferation of the mouse myeloid cell line 32D clone 3 (32Dcl3) via TNF- $\alpha$.

Introduction: Sodium caseinate (CS) and its components (alpha-casein, beta-casein, and kappa-casein) have been shown to inhibit the proliferation of the mouse hematopoietic 32D clone 3 (32Dcl3) cell line and induce its differentiation into macrophages. It is well-known that alpha-casein induces IL-1 $\beta$ production and that this cytokine inhibits the proliferation via the production of tumor necrosis factor alpha (TNF-alpha), but it is not known if CS and the caseins inhibit the proliferation via TNF-alpha production.

Objective: To evaluate if CS and alpha-casein, beta-casein and kappa-casein inhibit the proliferation on 32Dcl3 cell line via TNF-alpha.

Materials and methods: We used different concentrations of CS, alpha-casein, betacasein and kappa-casein in 32Dcl3 cells to evaluate cell proliferation. We assessed cell viability by MTT, induction to apoptosis by flow cytometry, and TNF-alpha synthesis by ELISA. Additionally, we performed anti-TNF-alpha neutralization assays on 32Dcl3 cells treated with CS and alpha-casein and we evaluated proliferation.

Results: The results showed that CS, alpha-casein, beta-casein, and kappa-casein reduced proliferation of the $32 \mathrm{Dcl} 3$ cell line without affecting the viability and that only $\mathrm{CS}$ and alpha-casein induced apoptosis and the release of TNF-alpha. The 32Dcl3 cells treated with CS and alpha-casein reestablished their proliferation by using anti-TNF-alpha antibodies.

Conclusion: TNF-alpha was the main responsible for the inhibition of proliferation in $32 \mathrm{Dcl} 3$ cells treated with CS or alpha-casein.

Keywords: Caseins; hematopoiesis; cell proliferation; apoptosis; tumor necrosis factor-alpha.
Conflicto de intereses:

Los autores declaran no tener conflictos de intereses. 
La leche y los productos lácteos son componentes importantes de la dieta humana e, históricamente, se les ha valorado por su aporte nutricional de aminoácidos (1). La leche bovina, la más frecuentemente consumida, está constituida por 3,6 \% de proteínas, $4,1 \%$ de grasas, 5,0 \% de carbohidratos, menos de $1 \%$ de vitaminas y minerales, y $86,6 \%$ de agua (2).

De la fracción proteica, la caseína es el principal ( 80 \%) componente y está presente en forma de micelas, partículas esféricas de dimensión no uniforme (3). La micela de la caseína está compuesta por cuatro subunidades polipeptídicas denominadas caseínas $\alpha_{\mathrm{s} 1}, \alpha_{\mathrm{s} 2}, \beta$ y $\mathrm{k}(4,5)$. En los últimos años se ha explorado su capacidad para influir en funciones hematopoyéticas normales (6) e, incluso, en la reacción inmunitaria de modelos animales por medio de la producción de citocinas como la IL-1 $\beta$ por parte de los macrófagos; de esta forma, la caseína puede actuar como reguladora del sistema inmunológico (7).

En este sentido, se ha observado que en las ratas alimentadas con caseína se reduce el desarrollo de tumores de colon, y se sugirió que dicho proceso involucraba al sistema inmunológico (8), en tanto que se ha reportado que la ingestión de caseína parece un evento obligado para la maduración del sistema inmunológico en las mucosas (9).

Por otro lado, se sabe que las casomorfinas, derivadas de la degradación proteolítica de las caseínas, inhiben la proliferación de las líneas celulares de cáncer de seno y de próstata $(10,11)$. Además, las caseínas $\alpha_{\mathrm{s} 1}, \alpha_{\mathrm{s} 2}, \beta$ y $\mathrm{k}, \mathrm{y}$ el caseinato de sodio, una sal que contiene las subunidades de la caseína, inhibieron la proliferación de las células mieloides 32D clone 3 (32Dcl3) de ratón al promover su diferenciación hacia macrófagos $(12,13)$.

Se evidenció que el caseinato de sodio y las caseínas indujeron la expresión del ARN mensajero (ARNm) del CD115, receptor de membrana para el factor estimulante de colonias de macrófagos (Macrophage-Colony Stimulating Factor, M-CSF) -también conocido como receptor M-CSFR (Macrophage-Colony Stimulating Factor Receptor) o proto-oncogen c-fms (Colony-Stimulating Factor-1 Receptor)-, el cual es un marcador comúnmente asociado a macrófagos, en tanto que la caseína a y el caseinato de sodio promueven la síntesis de M-CSF, una citocina involucrada en la diferenciación y la función de monocitos y macrófagos (13).

Se sabe que la caseína a induce la producción de IL-1 $\beta$ (14) y que esta citocina inhibe la proliferación de las células 32Dcl3 mediante la producción del factor de necrosis tumoral a (TNF- $\alpha)(15,16)$, pero se desconoce si el caseinato de sodio y las caseínas inhiben la proliferación de las células 32Dcl3 mediante la producción de TNF- $\alpha$.

En este estudio se analizó la posible inducción del TNF- $\alpha$ en las células 32Dcl3 por parte de las caseínas y su intervención en la inhibición de la proliferación. Los resultados indicaron que el caseinato de sodio y las subunidades de caseína inhibieron la proliferación, y que solo el caseinato de sodio y la caseína a estimularon la producción del TNF- $\alpha$ en las células 32Dcl3.

\section{Materiales y métodos}

\section{Citocinas y anticuerpos}

Se emplearon la interleucina-3 recombinante de ratón ( $r m \mathrm{LL}-3)$, el factor de necrosis tumoral $\alpha$ recombinante de ratón (rmTNF- $\alpha$ ) y el anticuerpo antifactor de necrosis tumoral $\alpha$ de ratón (anti-TNF- $\alpha$ ) (R\&D Systems, USA). 


\section{Cultivo celular}

La línea celular mieloide 32Dcl3 de ratón donada por T. Hoang (Hematopoiesis and Leukemia Laboratory, Montreal, Quebec, Canadá), se mantuvo en medio de cultivo Iscove's Modified Dulbecco's Medium (IMDM, Gibco BRL, USA) adicionado con $10 \%$ de suero fetal bovino previamente inactivado con calor (HyClone, Utah, USA), más $0,5 \mathrm{ng} / \mathrm{ml}$ de interleucina-3 recombinante de ratón (rmIL-3) como factor de crecimiento, mantenido a una temperatura de $37^{\circ} \mathrm{C}$ y con $5 \%$ de $\mathrm{CO}_{2}$.

En estas condiciones, se cultivaron células con caseinato de sodio y sin él $(2 \mathrm{mg} / \mathrm{ml}$ ) (Difco Laboratories, Detroit, MI, USA), y con caseínas $\alpha, \beta$ o $\mathrm{K}$ $(1 \mathrm{mg} / \mathrm{ml}$ ) (Sigma, México) en placas de 96 pozos (Costar, Cambridge, MA, USA) con una densidad de $2 \times 10^{4}$ células $/ \mathrm{ml}$. El medio condicionado se recolectó a las 72 horas de cultivo y se almacenó a $-70{ }^{\circ} \mathrm{C}$ hasta su uso.

\section{Proliferación celular}

Para evaluar la proliferación se cultivaron $2 \times 10^{4}$ células $/ \mathrm{ml}$ con caseinato de sodio o sin él, y caseína $\alpha, \beta$ o k en placas de 96 pozos (Corning NY, USA) en las condiciones antes señaladas durante 56 horas. Posteriormente, se adicionaron $0,5 \mu \mathrm{Ci}$ de $\left[\beta-{ }^{3} \mathrm{H}\right] \mathrm{dTTP} / \mathrm{ml}$ timidina (activity $185 \mathrm{mbq}$, Amersham Pharmacia Biotech, UK) y las células se cosecharon 16 horas más tarde. Después de lavar y lisar las muestras, se adicionaron $2 \mathrm{ml}$ de líquido de centelleo (Beckman, USA) y se cuantificó la emisión de luz en un contador de partículas beta (beta counter) (Beckman LS6500, USA).

\section{Viabilidad celular}

Se determinó la presencia de células viables mediante una prueba con el bromuro de MTT [3-(4,5-dimetiltiazol-2-ilo)-2,5-difeniltetrazol], para lo cual se adicionaron $20 \mu \mathrm{l}$ de MTT ( $5 \mathrm{mg} / \mathrm{ml}$ de solución salina) al cultivo en placas de 96 pozos, y luego se incubó durante cuatro horas a $37^{\circ} \mathrm{C}$. Posteriormente, las células se lisaron y disolvieron con $100 \mu \mathrm{l}$ de $0,04 \mathrm{~N}$ de ácido clorhídrico $(\mathrm{HCl})$ en isopropanol, estableciendo la absorbancia a $590 \mathrm{~nm}$ en un lector de placas (Tecan Spectra, Austria).

\section{Apoptosis}

Para detectar la presencia de células positivas para fosfatidilserina como criterio de positividad de las células apoptóticas, se utilizó el estuche PHN1018 de anexina-V-FITC ${ }^{\text {TM }}$ (Biosource); la fluorescencia se analizó en un citómetro de flujo (Becton Dickinson, San José, CA), según los procedimientos estándar.

\section{Prueba inmunoenzimática}

Para detectar la presencia de TNF- $\alpha$ en el medio condicionado de células con tratamiento de caseinato de sodio o caseínas y sin este, se utilizó el estuche KMC3012 de ELISA (Biosource, USA) conforme a las especificaciones del fabricante y se determinó la absorbancia a $450 \mathrm{~nm}$ en un lector de placas (Tecan Spectra, Austria).

\section{Neutralización del TNF- $\alpha$ en cultivos con caseinato de sodio o caseína a}

Para neutralizar la actividad del TNF- $\alpha$ en cultivos con caseinato de sodio o caseína a y sin estos, se adicionaron $2 \times 10^{4} \mathrm{cel} / \mathrm{ml}$ de un anticuerpo neutralizador anti-TNF- $\alpha$ en placas de 96 pozos y se consideraron los 
controles de rmTNF- $\alpha$, rmTNF- $\alpha$ más el anticuerpo anti-TNF- $\alpha$ y únicamente anticuerpo anti-TNF- $\alpha$, evaluando la proliferación como se ha indicado.

\section{Resultados}

\section{El caseinato de sodio y las caseínas $\alpha, \beta$ o $\mathrm{k}$ inhiben la proliferación sin afectar la viabilidad de las células 32Dcl3.}

Para mostrar que el caseinato de sodio y las caseínas inhiben la proliferación de las células 32Dcl3, estas se cultivaron en presencia de 0,5 $\mathrm{ng} / \mathrm{ml}$ de rmlL-3, con o sin caseinato de sodio, y las caseínas $\alpha, \beta$ o $\mathrm{k}$ durante 72 horas. Los resultados evidenciaron que, a partir de $0,5 \mathrm{mg} / \mathrm{ml}$ de caseinato de sodio y de caseína $\alpha$ o $\mathrm{k}$ y $0,1 \mathrm{mg} / \mathrm{ml}$ de caseína $\beta$, la proliferación celular se bloqueó significativamente (figura 1) sin afectar la viabilidad que, en todos los casos, fue superior al $90 \%$ (cuadro 1).

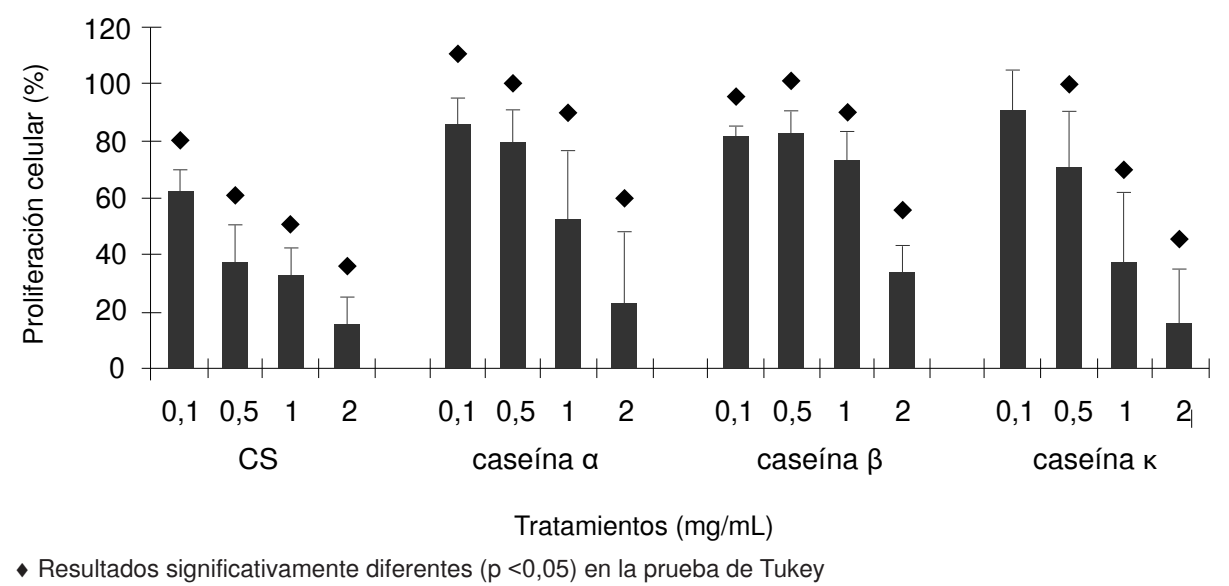

Figura 1. Proliferación de la línea celular 32D cl3 después de 72 horas de incubación en presencia de $0,5 \mathrm{ng} / \mathrm{ml}$ de rmlL-3, con o sin el inductor caseinato sódico y las caseínas $\alpha, \beta$ o $\mathrm{k}$ en diferentes dosis. La proliferación se muestra como el porcentaje incorporado de timidina [3H] con respecto al control.

Cuadro 1. Porcentaje de viabilidad celular determinada mediante pruebas con MTT de la línea celular 32D cl3 tratada con caseinato de sodio y caseínas $\alpha, \beta$ y $\mathrm{k}$ después de tres días de incubación. Cuantificación del TNF- $\alpha$ mediante ELISA en medios acondicionados de línea celular $32 \mathrm{D} \mathrm{cl} 3$ sin inductor, caseinato de sodio o caseínas. Los datos muestran el promedio \pm desviación estándar (DE).

\begin{tabular}{ccc}
\hline Tratamientos & Viabilidad celular $(\%)$ & TNF- $\boldsymbol{\alpha}(\mathbf{n g} / \mathbf{m l})$ \\
\hline Sin inductor & $98 \pm 1,3$ & $0,00 \pm 0,000$ \\
Caseinato de sodio & $91 \pm 2,5^{\star}$ & $2,19 \pm 0,297^{\star}$ \\
Caseína a & $94 \pm 6,5$ & $0,40 \pm 0,064^{*}$ \\
Caseína $\beta$ & $96 \pm 4,5$ & $0,00 \pm 0,000$ \\
Caseína k & $93 \pm 6,3$ & $0,00 \pm 0,000$ \\
\hline
\end{tabular}

* Resultados significativamente diferentes de la línea 32D sin inductor $(p<0,05)$ en la prueba de Dunnet

Una forma de evaluar el compromiso indicativo de un posible daño celular es la detección de la translocación de la fosfatidilserina de la cara interna a la externa de la membrana celular, lo que indica apoptosis. Los datos obtenidos de la citometría de flujo indicaron que el 23, el 16, el 10 y el $8 \%$ de la población presentó translocación en la región de apoptosis tardía en presencia de caseinato de sodio, y de las caseínas $\alpha, \beta \circ \mathrm{K}$, respectivamente, mientras que en el control esta proporción fue de $4 \%$ (figura 2). 


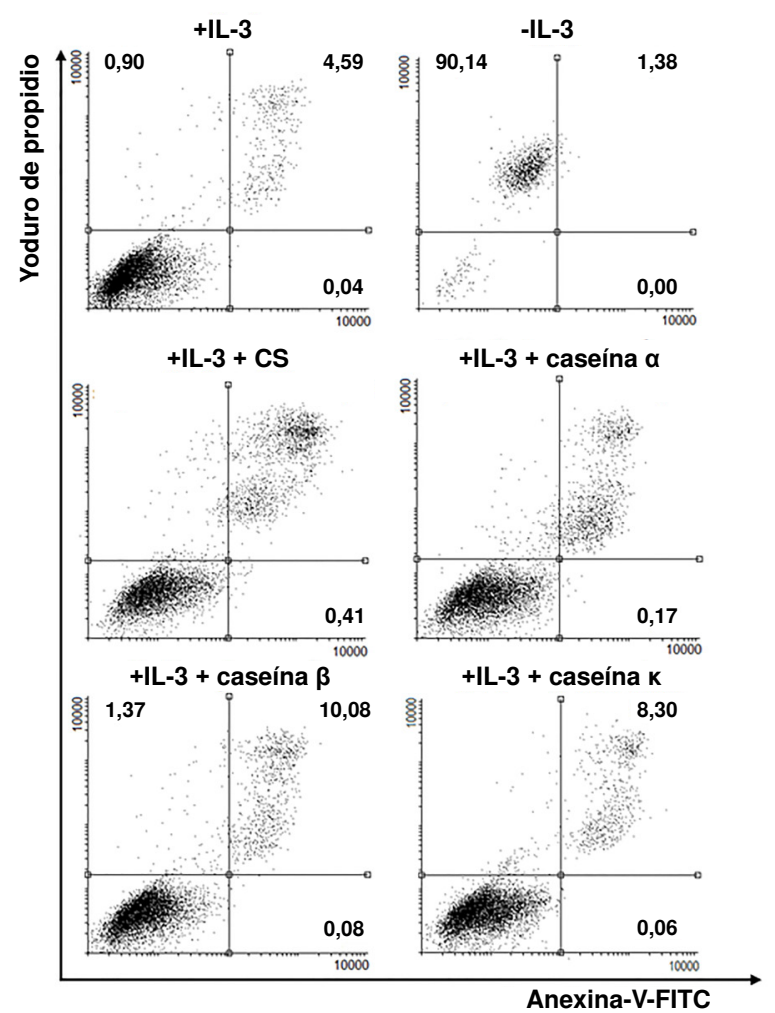

Figura 2. Línea celular 32D cl3 en presencia de $0,5 \mathrm{ng} / \mathrm{ml}$ de $\mathrm{rmlL}-3$ incubada con $2 \mathrm{mg} / \mathrm{ml}$ de caseinato de sodio y con las caseínas $\alpha, \beta$ y . Se detecta apoptosis por tinción dual de anexina $\checkmark$ y yoduro de propidio. Además, se incluye la línea celular $32 \mathrm{D}$ cl3 incubada sin rmlL-3 como control de la muerte celular.

\section{El caseinato de sodio y la caseína $\beta$ indujeron la producción de TNF-a en las células 32Dc/3.}

La inducción de la apoptosis puede ser mediada por TNF-a, por lo que al evaluar su presencia en el medio condicionado de células con tratamiento de caseinato de sodio o caseínas, o sin este, la prueba de ELISA evidenció que $2 \mathrm{mg} / \mathrm{ml}$ de caseinato de sodio y $1 \mathrm{mg} / \mathrm{ml}$ de caseína a inducían la liberación de dicho factor (cuadro 1). En este sentido, aun cuando la adición de la caseína $\beta$ o la $\mathrm{k}$ redujo de manera significativa la proliferación, los resultados del ELISA indicaron que no inducían la liberación del TNF- $\alpha$.

\section{EI TNF-a fue responsable de la inhibición de la proliferación en cultivos con caseinato de sodio y caseína $\beta$.}

Al constatar que el TNF intervenía en la inhibición de la proliferación de las células $32 \mathrm{Dcl} 3$, se procedió a demostrar que estas eran sensibles al efecto del TNF-a recombinante. Los resultados indicaron que sí inhibió la proliferación de 32Dcl3 según la dosis utilizada (figura 3). Una vez se evidenció que el TNF- $\alpha$ recombinante inhibía la proliferación de las células 32Dcl3, se procedió a avaluar si el TNF-a producido por las células 32Dcl3 tratadas con caseinato de sodio o caseína a era el responsable de inhibir la proliferación. El uso de anticuerpos anti-TNF- $\alpha$ de ratón en células 32Dcl3 tratadas con caseinato de sodio y caseína a previno la inhibición de la proliferación en más de $80 \%$ en las células tratadas con caseinato de sodio y en $100 \%$ en las células tratadas con caseína a (figura 4). 


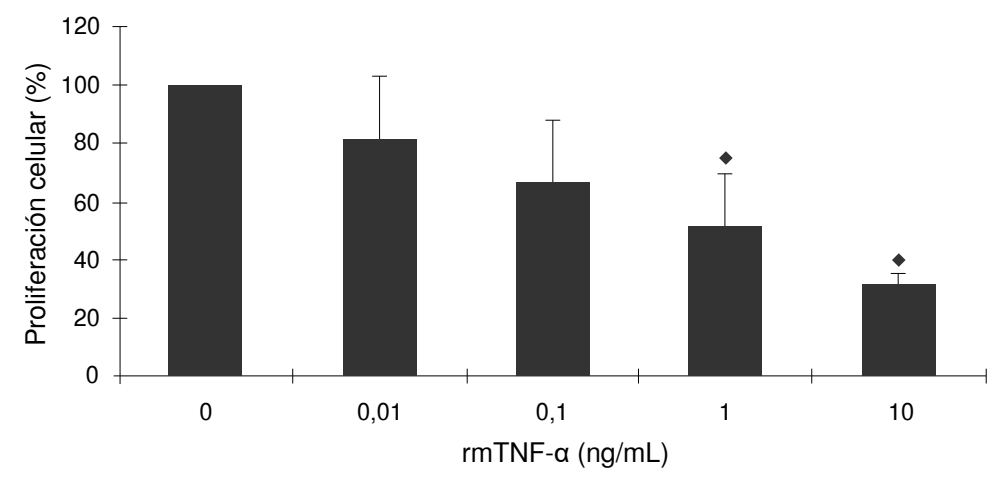

- Resultados significativamente diferentes $(p<0,05)$ en la prueba de Dunnet

Figura 3. Proliferación de la línea celular 32D cl3 después de 48 horas de incubación en presencia de $0,5 \mathrm{ng} / \mathrm{ml}$ de $\mathrm{rmlL}-3$, con o sin inductor rmTNF- $\alpha$ en diferentes dosis. La proliferación se muestra como el porcentaje de incorporación de timidina $[3 \mathrm{H}]$ con respecto al testigo $(0 \mathrm{mg} / \mathrm{ml})$.

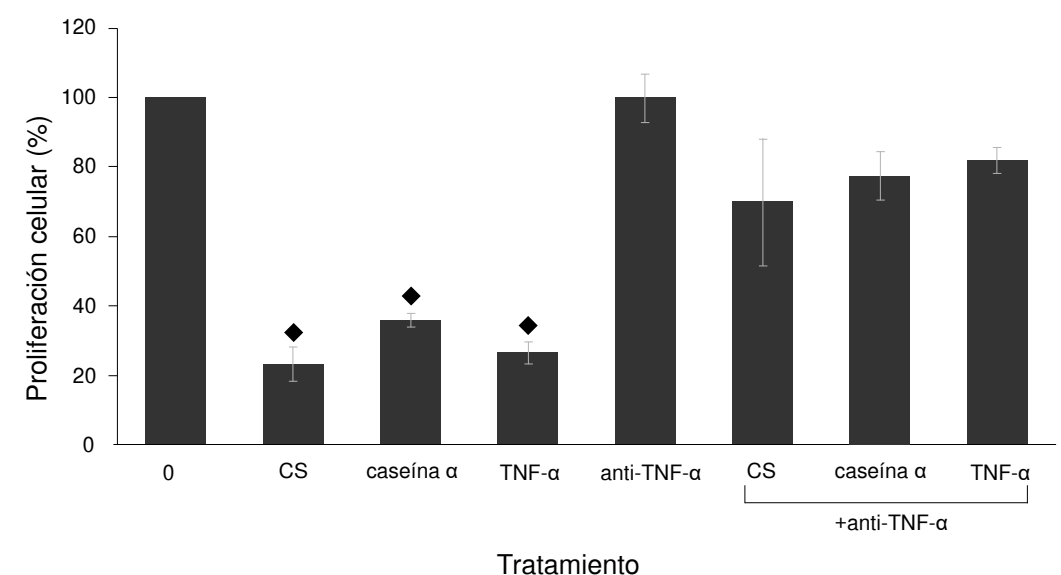

- Resultados significativamente diferentes $(p<0,05)$ en la prueba de Tukey

Figura 4. Proliferación de la línea celular 32D cl3 después de 72 horas de incubación en presencia de $0,5 \mathrm{ng} / \mathrm{ml}$ de $\mathrm{rmlL}-3$ con $2 \mathrm{mg} / \mathrm{ml}$ de caseinato de sodio y caseína $\alpha$, o $10 \mathrm{ng} / \mathrm{ml}$ de rmTNF- $\alpha$ más $16 \mu \mathrm{g} / \mathrm{ml}$ de anticuerpo anti-TNF- $\alpha$, o solo anti-TNF- $\alpha$

\section{Discusión}

Se ha demostrado que el caseinato de sodio y la caseína a son capaces de inhibir la proliferación en las células mieloides 32Dcl3 de ratón (12). En este trabajo se muestra que estimulan la liberación del TNF-a, el cual es el principal agente supresor de la proliferación en las células tratadas con caseinato de sodio y el responsable de la inhibición mediada por la caseína $\alpha$.

En algunos estudios se ha encontrado que la caseína $\alpha$ induce la producción de TNF- $\alpha$ en líneas celulares de monocitos y macrófagos $(15,17)$ e, incluso, en células dendríticas (18). En el presente estudio se evidenció que también lo hace en la línea celular mieloide de ratón dependiente de interleucina-3 32Dcl3, una línea hematopoyética capaz de diferenciarse en eritrocitos, granulocitos y macrófagos (15), lo cual indica que la caseína $\alpha$, al igual que el caseinato de sodio, regula el funcionamiento de células del sistema inmunológico e, incluso, la generación de células hematopoyéticas.

Es claro que el caseinato de sodio y la caseína a inhiben la proliferación de células 32Dcl3 por medio de la producción de TNF- $\alpha$; además, ambos inducen la producción del factor estimulador de colonias de 
macrófagos en la misma línea celular (13). Esto sugiere que pueden activar mecanismos similares, a diferencia de las caseínas $\beta$ y $\mathrm{k}$, las cuales inhiben la proliferación, pero no lo hacen por medio del TNF- $\alpha$, por ello, sería interesante evaluar la participación de otras citocinas inhibidoras de progenitores hematopoyéticos, como el interferón a, que induce la producción de inhibidores de la progresión del ciclo celular en células troncales y progenitoras hematopoyéticas (19).

Se sabe que la caseína activa los macrófagos mediante la unión al receptor TLR4 (20) y es probable que en la línea mieloide normal de ratón dependiente de interleucina-3 32Dcl3, que es una progenitora hematopoyética (16), lo haga por medio del mismo tipo de receptores, ya que se sabe que las células troncales y progenitoras hematopoyéticas también expresan los receptores TLR4 (21).

Es interesante señalar que, siendo la subunidad de mayor representatividad entre las micelas de la caseína (20), la caseína a en asociación con el caseinato de sodio ejerza efectos similares a este en cuanto a la proliferación e, incluso, la diferenciación y la expresión de citocinas. En este sentido, dado que las caseínas presentan en su estructura péptidos bioactivos, algunos de ellos con características opioides $(22,23)$, sería interesante determinar si alguno de estos es el responsable de la inducción del TNF- $\alpha$ en las células 32Dcl3 tratadas con caseína $\alpha$.

Nuestros datos revelan que ni las caseínas ni el caseinato de sodio alteran la viabilidad celular detectada mediante el MTT, una prueba que evidencia la actividad metabólica mitocondrial (que solo tiene lugar en células vivas) (24), lo cual no coincide con la ligera inducción de translocación de fosfatidilserina causada por todas las caseínas, especialmente, por el caseinato de sodio (23\%) y la caseína a (16\%), justamente en las condiciones en que se observa la liberación de TNF-a, un promotor de la inducción de la apoptosis (25). La translocación de fosfatidilserina a la cara externa de la membrana es un evento temprano de inducción de la apoptosis y, por lo tanto, es reversible (26). Por ello, bajo estas condiciones es probable que la funcionalidad mitocondrial aún no se encontrara comprometida en el presente estudio (27) y que la viabilidad siguiera intacta. Sin embargo, sabiendo que el TNF-a induce necroptosis (28), sería interesante analizar si las caseínas activan esta ruta de muerte.

Por último, la línea celular 32Dcl3 se considera normal porque no es cancerígena y, habiendo demostrado que las caseínas no inducen la muerte celular en las células hematopoyéticas de médula ósea normal (12), puede decirse que se tienen los modelos para estudiar los mecanismos de eliminación de células en proceso de transformación celular y de aquellas propiamente tumorales, pero no de las verdaderamente normales, tal como lo hace la caseína.

En conclusión, las caseínas $\alpha, \beta$ y $\mathrm{k}$ inhiben la proliferación de las células 32Dcl3 de manera análoga al caseinato de sodio y el rmTNF- $\alpha$. El caseinato de sodio y la caseína $\alpha$, pero no así las caseínas $\beta$ o K, inducen la producción de TNF- $\alpha$ en las células 32Dcl3, y este factor es el principal responsable de la inhibición de la proliferación en cultivos con caseína a y caseinato de sodio.

\section{Agradecimientos}

A Ranulfo Pedraza Garnelo ${ }^{\dagger}$ y Sandra Salazar Aguilar por el apoyo técnico brindado. 


\section{Referencias}

1. Koletzko B, Agget PJ, Bindels JG, Bung P, Ferré P, Gil A, et al. Growth development and differentiation: A functional food science approach. Br J Nutr. 1998;80:5-45. https://doi.org/10.1079/BJN19980104

2. Kon S. Milk and milk products in human nutrition. Second edition. Rome: FAO Nutr Stud; 1977.

3. Walstra P, Jenness R. Dairy chemistry and physics. First edition. New York, USA: Wiley and Sons, 1984.

4. Warner J. Principios de la tecnología de lácteos. 1ª edición. México: AGT; 1976.

5. Hall C. Drying of milk and products. Second edition. Conneticut, USA: The Avi Pub Company Inc.; 1971.

6. Okano M, Ohnota H, Sasaki R. Protein deficiency impairs erythropoiesis in rats by reducing serum erythropoietin concentration and the population size of erythroid precursor cells. J Nutr. 1992;122:1376-83. https://doi.org/10.1093/jn/122.7.1376

7. Wong CW, Seow HF, Liu AH, Husband AJ, Smithers GW, Watson DL. Modulation of immune responses by bovine $\beta$-casein. Immunol Cell Biol. 1996;74:323-9. https://doi.org/10.1038/icb.1996.58

8. Tatsuta M, Lishi H, Baba M, Taniguchi H. Enhanced induction of colon carcinogenesis by azoxymethane in wistar rats fed a low-protein diet. Int J Cancer. 1992;50:108-11. https://doi.org/10.1002/ijc.2910500122

9. da Silva-Menezes J, de Sousa-Mucida D, Carmona-Cara D, Alvarez-Leite JL, Russo M, Vaz $\mathrm{NM}$, et al. Stimulation by food proteins plays a critical role in the maturation of the immune system. Int Immunol. 2003;15:447-55. https://doi.org/10.1093/intimm/dxg043

10. Kampa M, Loukas S, Hatzoglou A, Martin P, Castanas E. Identification of a novel opioid peptide (Tyr-Val-Pro-Phe-Pro) derived from human alpha S1 casein (alpha S1-casomorphin, and alpha S1-casomorphin amide). Biochem J. 1996;319:903-8. https://doi.org/10.1042/bj3190903

11. Hatzoglou A, Bakogeorgou E, Hatzoglou C, Martin PM, Castanas E. Antiproliferative and receptor binding properties of a-and $\beta$-casomorphins in the T47D human breast cancer cell line. Eur J Pharmacol. 1996;310:217-23. https://doi.org/10.1016/0014-2999(96)00339-1

12. Ramos-Mandujano G, Weiss-Steider B, Melo B, Córdova Y, Ledesma-Martínez E, Bustos $\mathrm{S}$, et al. Alpha-, beta- and kappa-caseins inhibit the proliferation of the myeloid cell lines $32 \mathrm{D} \mathrm{cl} 3$ and WEHI-3 and exhibit different differentiation properties. Immunobiology. 2008;213:133-41. https://doi.org/10.1016/j.imbio.2007.07.004

13. Ramos G, Weiss B, Córdova Y, Hernández J, Zambrano I, Santiago E. Sodium caseinate induces expression and secretion of the murine multipotent myeloid cell line 32D macrophage colonystimulating factor. Arch Med Res. 2004;35:109-13. https://doi.org/10.1016/j.arcmed.2003.11.001

14. Vordenbaumen S, Saenger T, Braukmann A, Tahan T, Bleck E, Jose J, et al. Human casein alpha $\mathrm{s} 1$ induces proinflammatory cytokine expression in monocytic cells by TLR4 signaling. Mol Nutr Food Res. 2016;60:1079-89. https://doi.org/10.1002/mnfr.201500792

15. Kharbanda S, Nakamura T, Datta R, Sherman ML, Kufe D. Induction of monocytic differentiation by tumor necrosis factor in phorbol ester-resistant KG-1a cells. Cancer Commun. 1990;2:327-32.

16. Ledesma E, Martínez L, Córdova Y, Rodríguez-Sosa M, Monroy A, Mora L, et al. Interleukin-1 (IL-1 $\beta$ ) induces tumor necrosis factor alpha (TNF-a) expression on mouse myeloid multipotent cell line 32D cl3 and inhibits their proliferation. Cytokine. 2004;26:66-72. https://doi.org/10.1016/j.cyto.2003.12.009

17. Weber C, Aepfelbacher M, Haag H, Ziegler-Heitbrock HW, Weber PC. Tumor necrosis factor induces enhanced responses to platelet-activating factor and differentiation in human monocytic Mono Mac 6 cells. Eur J Immunol. 1993;23:852-9. https://doi.org/10.1002/eji.1830230413

18. Daneshmandi S, Nourizadeh M, Pourpak Z, Pourfathollah AA. Eliciting Th1 immune response using casein- (Alpha S1) loaded dendritic cells. Iran J Allergy Asthma Immunol. 2017;16:159-68.

19. Smith JN, Kanwar VS, MacNamara KC. Hematopoietic stem cell regulation by type I and II interferons in the pathogenesis of acquired aplastic anemia. Front Immunol. 2016;29:1-13. https://doi.org/10.3389/fimmu.2016.00330 
20. Tobita K, Kawahara T, Otani H. Bovine beta-casein (1-28), a casein phosphopeptide, enhances proliferation and IL-6 expression of mouse CD19+ cells via Toll-like receptor 4. J Agric Food Chem. 2006;54:8013-7. https://doi.org/10.1021/j0610864

21. Megías J, Yáñez A, Moriano S, O’Connor JE, Gozalbo D, Gil ML. Direct Toll-like receptormediated stimulation of hematopoietic stem and progenitor cells occurs in vivo and promotes differentiation toward macrophages. Stem Cells. 2012;30:1486-95. https://doi.org/10.1002/stem.1110

22. Otani H, Hata I. Inhibition of proliferative responses of mouse spleen lymphocytes and rabbit Peyer's patch cells by bovine milk caseins and their digests. J Daily Res. 1995;62:339-48. https://doi.org/10.1017/S0022029900031034

23. Meisel H. Biochemical properties of peptides encrypted in bovine milk protein. Current Med Chem. 2005;12:1905-19. https://doi.org/10.2174/0929867054546618

24. Kharbanda S, Nakamura T, Datta R, Sherman ML, Kufe S. Induction of monocytic differentiation by tumor necrosis factor in phorbol ester-resistant KG-1a cells. Cancer Commun. 1990;2:327-32. https://doi.org/10.3727/095535490820874074

25. Dong QM, Ling C, Chen X, Zhao L. Inhibition of tumor necrosis factor-a enhances apoptosis induced by nuclear factor-KB inhibition in leukemia cells. Oncol Lett. 2015;10:3793-8. https://doi.org/10.3892/ol.2015.3786

26. Amarante-Mendes GP, Green DR. The regulation of apoptotic cell death. Braz J Med Biol Res. 1999;32:1053-61. https://doi.org/10.1590/S0100-879X1999000900001

27. Wang JS, Wu-D'Huang DY, Lin WW. TAK1 inhibition-induced RIP1-dependent apoptosis in murine macrophages relies on constitutive TNF-a signaling and ROS production. J Biomed Sci. 2015;22:22-76. https://doi.org/10.1186/s12929-015-0182-7

28. Morgan JE, Prola A, Mariot V, Pini V, Meng J, Hourde C, et al. Nectroptosis mediates myofibre death in dystrophin-deficient mice. Nat Commun. 2018;9:3655. https://doi.org/10.1038/s41467-018-06057-9 